\title{
IrReAlidad Aumentada: EL Mito, el ARTE POLÍTICO Y EL ESPECTADOR
}

Augmented irreality: myth, political art and the spectator

\author{
MITO Collective \\ Colectivo artístico basado en Barcelona \\ info@mito.tv \\ Quim Bonastra \\ ORCID: 0000-0002-4717-8450 \\ Joan Deulofeu \\ Ana María Álvarez \\ Enrique Baeza
}

RESUMEN: A partir del proyecto de arte colaborativo en el espacio público Irrealidad aumentada llevado a cabo por MITO Collective durante la pandemia de Covid-19, los miembros del colectivo artístico nos hacemos preguntas que nos ayudan a pensar de un modo teórico y especulativo sobre la noción de mito que está en el principio de nuestro proyecto. A través de las diferentes secciones del artículo hablaremos de una noción actualizada de mito y cómo esta noción, aplicada a la pandemia, es productiva en la definición de un arte político y una comunidad y un espectador que se erigen como sujeto político.

Palabras clave: Pandemia, COVID-19, arte, público, creador, espectador, mito, política.

ABSTRACT: Based on the collaborative art project in the Augmented Irreality public space, carried out by MITO Collective during the Covid-19 pandemic, as members of the artistic collective we ask ourselves questions that help us think theoretically and speculate about the notion of myth that lies in the origins of our project and how this notion, applied to the pandemic, is productive in defining a political art and a community and a spectator that emerge as a political subject.

KeYWORDs: Pandemic, COVID-19, art, public, creator, spectator, myth, politics. 
RESUM: A partir del projecte d'art col-laboratiu en l'espai públic Irrealitat augmentada dut a terme per MITE Collective durant la pandèmia de Covid19 , els membres del col·lectiu artístic ens fem preguntes que ens ajuden a pensar d'una manera teòrica $\mathrm{i}$ especulativa sobre la noció de mite que està en el principi del nostre projecte. A través de les diferents seccions de l'article parlarem d'una noció actualitzada de mite i com aquesta noció, aplicada a la pandèmia, és productiva en la definició d'un art polític i una comunitat i un espectador que s'erigeixen com a subjecte polític.

Paraules clau: Pandèmia, COVID-19, art, públic, creador, espectador, mite, política. 


\section{Introducción}

Durante el confinamiento domiciliario exigido por las autoridades de casi todos los países del mundo a causa de la pandemia mundial de COVID-19, desde MITO Collective ${ }^{1}$ pusimos en marcha el proyecto Irrealidad Aumentada, que mientras escribimos estas líneas todavía sigue en marcha.

Este proyecto nació del diálogo con la ciudadanía de Barcelona, a la que interpelamos para saber qué pensamientos, ideas o reflexiones nos podían aportar para entender mejor la pandemia. De la interacción con los ciudadanos surgieron los lemas como:

Irrealidad aumentada, Imperio líquido,

Snacks \& doctrina,

Hackers \& cuerpos,

Espejismo lúcido,

Misterio Diáfano,

Vida Ficción o

Matrix Sostenible.

Lemas que reflejaban de un modo no taxativo, las angustias, inquietudes, impresiones y deseos de la ciudadanía y que, en su inconcreción, podían ser apropiados por la ciudadanía que se convertía en la protagonista del proceso artístico de acuerdo con nuestra idea de trabajar:

Ciudadanos como artistas y

artistas como ciudadanos.

Por esta razón contactamos con ciudadanos de los cinco continentes para que proyectaran estos lemas desde el encierro de sus casas hacia las fachadas de enfrente de sus casas, compartiéndolas con sus vecinos, y documentaran el acto.

1. MITO Collective es un colectivo artístico transdisciplinar formado por Quim Bonastra, Enrique Baeza, Ana María Álvarez y Joan Deulofeu que trabaja a partir de los mitos emergentes en nuestra contemporaneidad. https://mito.tv/about/. 


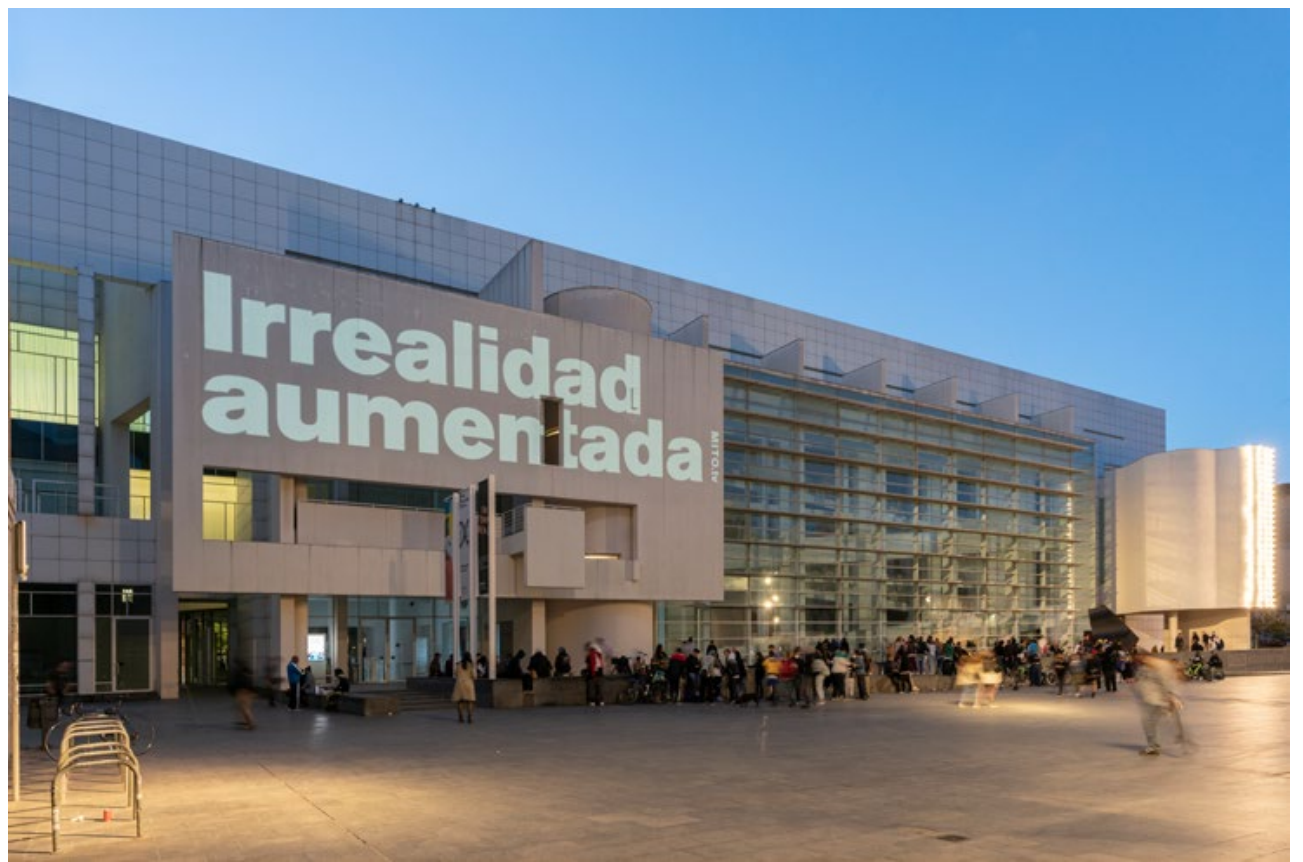

Figura 1. El lema Irrealidad aumentada sobre la fachada del MACBA, Barcelona, España. Fuente: Irrealidad Aumentada. MITO Collective (2021).

En las próximas páginas veremos de qué estamos hablando desde MITO Collective cuando hablamos de mitos y cómo trabajar desde esta noción nos ayuda a pensar la complejidad del mundo y de lo que nos concierne, lo que Isabelle Stengers (2018) resume en su concepto de cosmopolítica:

What I call cosmopolitics is [...] a name calling for the invention of modes of gathering that complicate politics by introducing hesitation (249).

En su propuesta, Stengers habla de civilizar la ciencia haciéndola más democrática, abierta a la sociedad y responsable de sus actos y de las consecuencias de ellos, introduciendo la complejidad y la duda como partes inherentes del proceso y entendiendo la escucha y el prestar atención como herramientas esenciales. Algo parecido es lo que pretendemos desde MITO Collective, aplicándolo al campo del arte y de la mediación cultural. 


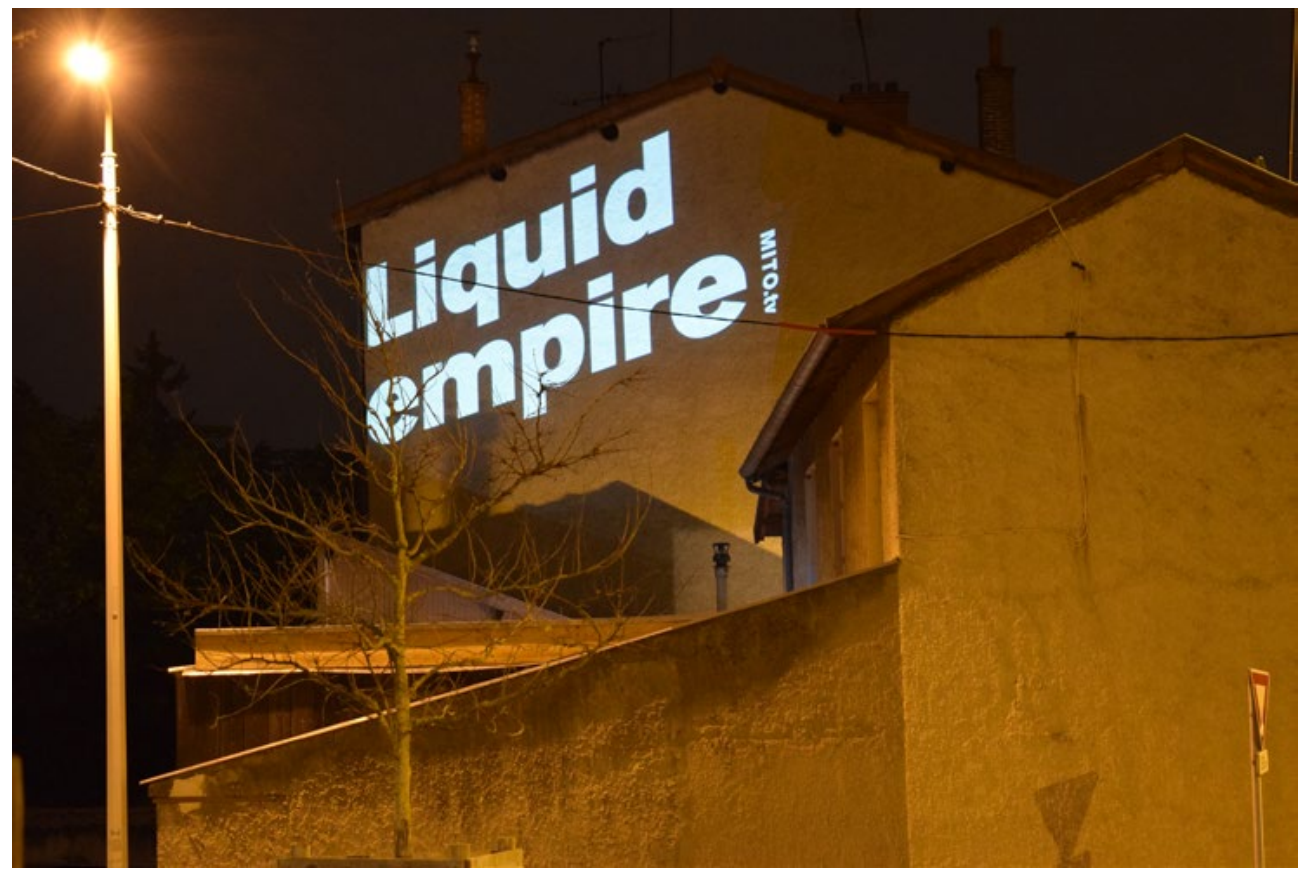

Figura 2. El lema Imperio Líquido sobre una fachada en Lyon, Francia. Fuente: Irrealidad Aumentada. MITO Collective (2021).

\section{Sobre la noción de mito}

Mucho se ha escrito sobre la pandemia durante la pandemia; parecía que de un modo precipitado quisiéramos explicarnos en qué habíamos fallado, qué posibilidades había de enmienda, cómo todo ello debía utilizarse para sentar las bases de una nueva era que estaba por venir y que se vislumbraba cada vez más cerca y con más claridad. Pasada la primera ola pandémica — la que había supuesto la operación de encierro domiciliario más numerosa, con su escala planetaria, y dilatada de la historia de la humanidad - entramos en el bucle de un oleaje pandémico que hizo que nos diéramos cuenta de que, en general, nada o muy poco iba a cambiar. 


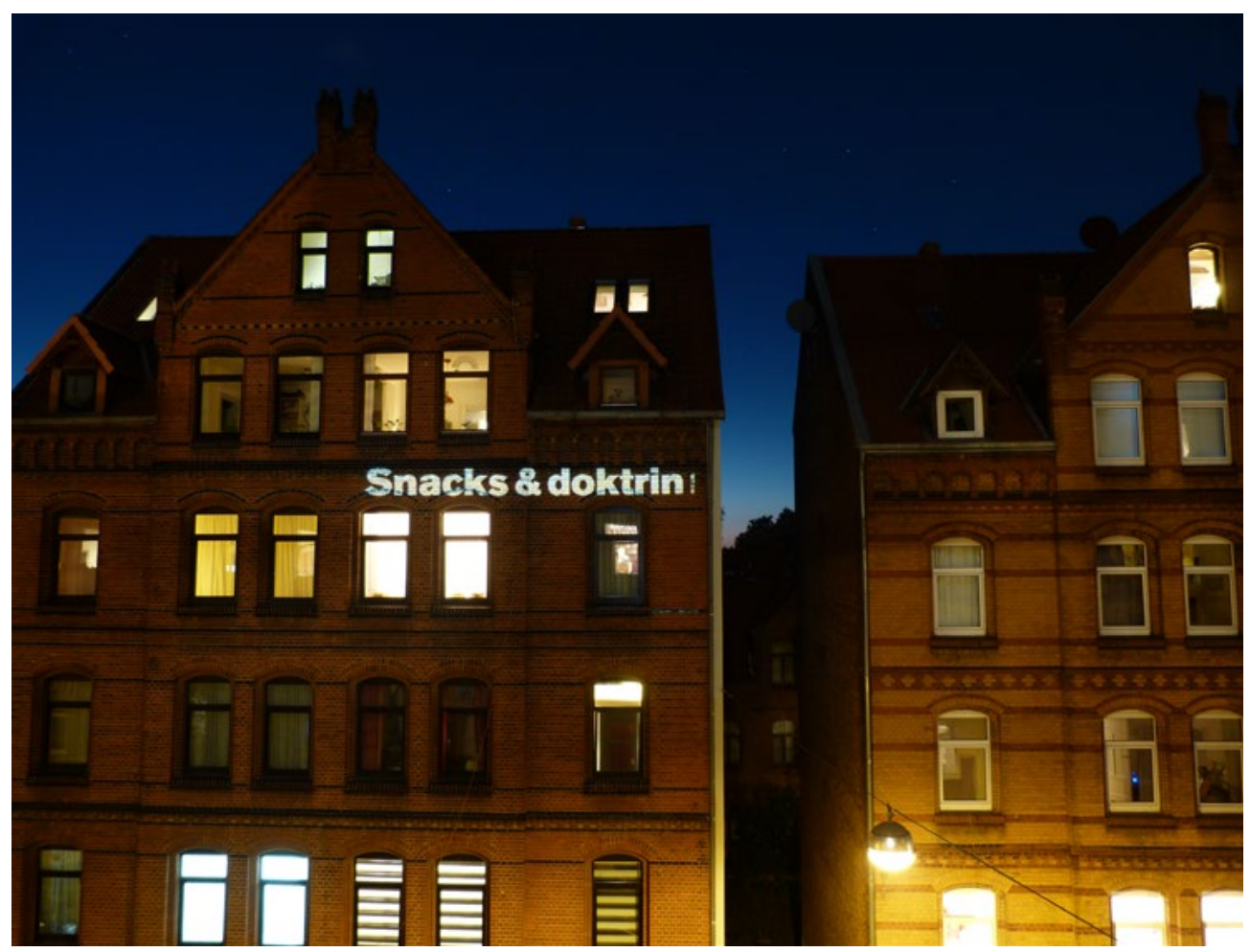

Figura 3. El lema Snacks \& doctrina sobre una fachada en Hannover, Alemania. Fuente: Irrealidad Aumentada. MITO Collective (2021).

En este marco, el análisis que de todo ello hizo Alessandro Baricco en Lo que estábamos buscando (2021) nos interesa por dos razones principales: en primer lugar por una razón obvia y cercana a la razón de ser de nuestro colectivo artístico, porque pone al día la noción de mito de un modo que, a grandes rasgos, coincide con nuestros postulados; en segundo lugar, porque trata la pandemia como una criatura mítica lo que, en cierto modo también coincide con alguna de las idea de fondo de nuestro proyecto. A lo largo del texto abordaremos ambas temáticas en relación con nuestro proyecto.

Los proyectos que realizamos desde MITO Collective tienen como denominador común el hecho de que se intentan sumergir e indagar en los mitos, en las criaturas míticas, que los humanos construimos en la contemporaneidad con la colaboración de la ciudadanía. 


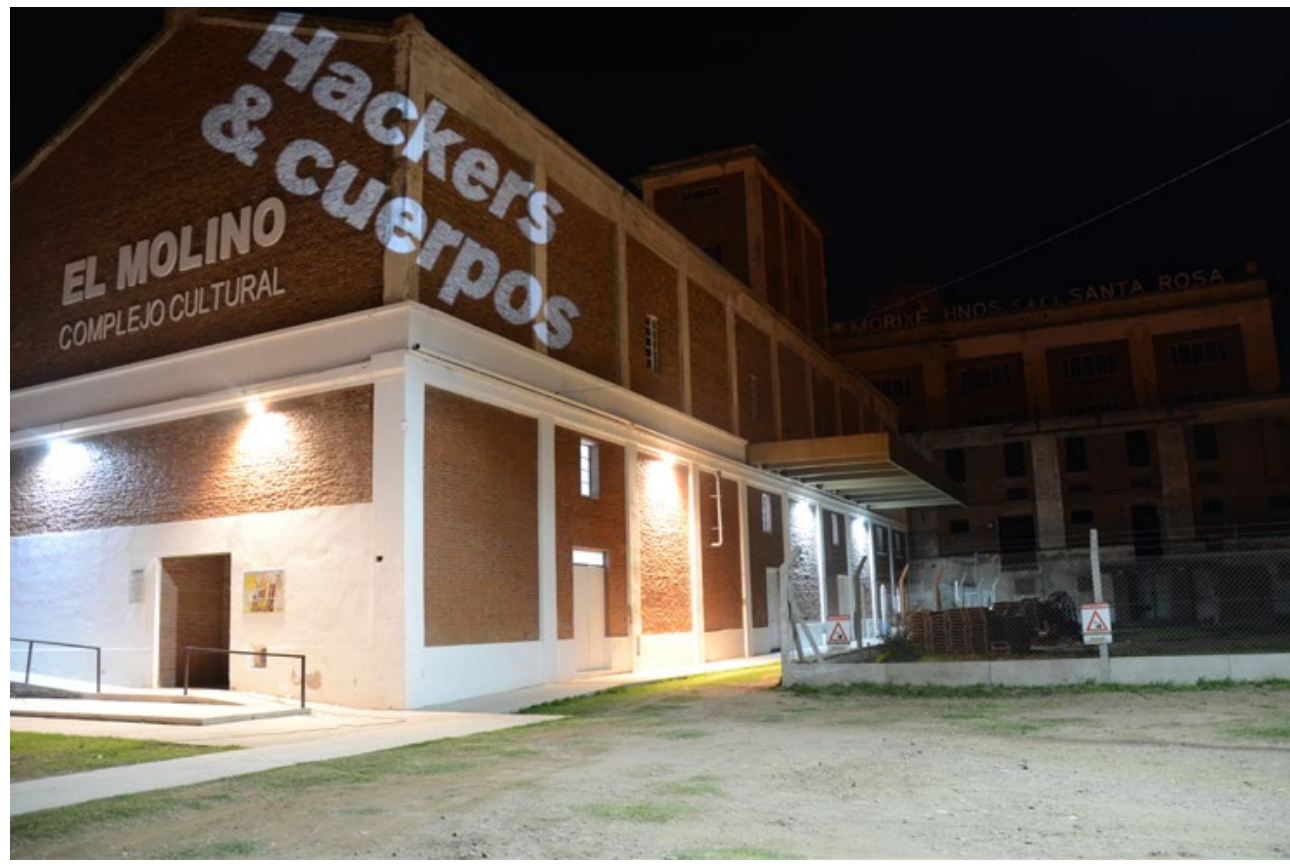

Figura 4. El lema Hackers \& cuerpos sobre la fachada del Complejo Cultural El Molino en Santa Rosa, Argentina.

Fuente: Irrealidad Aumentada. MITO Collective (2021).

\section{Como explica Baricco,}

las criaturas míticas son productos artificiales con los que los seres humanos se dicen a sí mismos algo urgente y vital. Son figuras en las que una comunidad de seres vivos organiza el material caótico de sus miedos, creencias, recuerdos o sueños. Estas criaturas habitan un espacio mental que llamamos mito (Baricco, 2021, p. 9).

Estas criaturas, que desde el racionalismo científico occidental creemos fruto de imaginaciones o de deformaciones de las narraciones hegemónicas derivadas de él, son, en realidad, maneras muy efectivas de lidiar con la realidad en la que vivimos y, en consecuencia, herramientas que configuran nuestras vidas y nuestras maneras de ver el mundo puesto que el mito "forma parte de nuestro sistema de realidad" (Baricco, 2021, p. 21).

En el mito, como parte de un sistema de realidad se ensamblan una gran cantidad de pequeños y grandes comportamientos prácticos aunque también participan de este ensamblaje objetos de muy distinta naturaleza: pangolines, murciélagos, mercados, aviones, políticas sanitarias, ministerios de sanidad, 
cuarentenas, hospitales, laboratorios, mascarillas, EPI, gel hidroalcohólico, filas, bombonas de oxígeno, gráficos, PCR, vacunas, camas de UCI, noticiarios, memes, canciones, balcones, aplausos, lemas, etc.

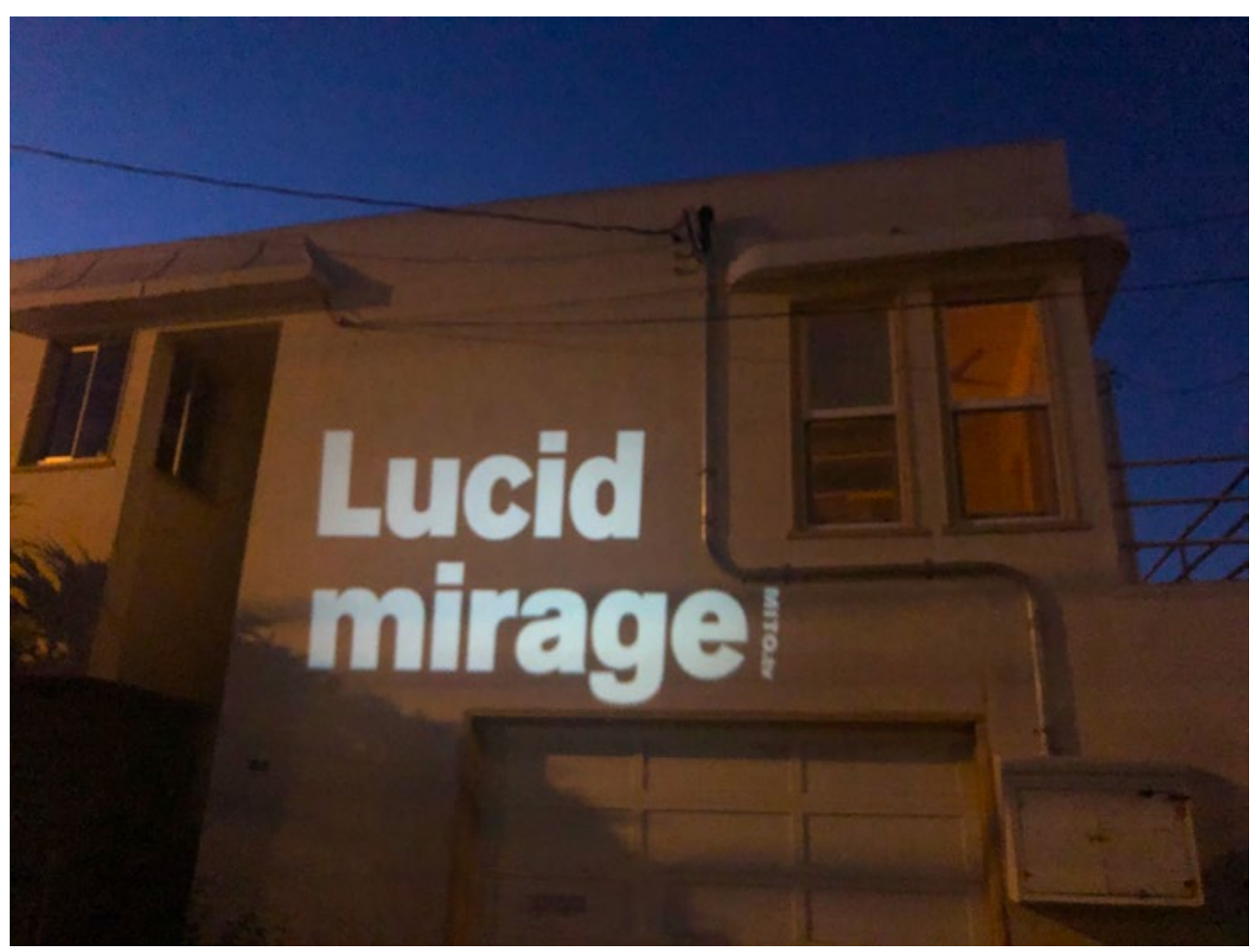

Figura 5. El lema Espejismo lúcido sobre una fachada en San Francisco, EUA. Fuente: Irrealidad Aumentada. MITO Collective (2021).

Así pues, a los mitos también hay que intentar entenderlos, ponerlos a prueba, regenerarlos, cuestionarlos y usarlos para generar nuevas realidades posibles. Hay que tener en cuenta el hecho de que los mitos no tienen una coherencia interna y operan en una red de potencialidades entre lo virtual (entendido como un problema a resolver y las múltiples capacidades para su resolución) y lo actual (entendido como todo lo que se nos aparece en una realidad espacio-temporal). En este espacio, el mito actúa como una máquina de actualización (es decir, una máquina que busca e implementa una solución a un problema, no necesariamente el único).

De este modo, entendemos que el mundo genera mitos y los mitos generan mundos... 


\section{El ciudadano como artista y el artista como ciudadano}

Irrealidad aumentada es un proyecto sobre la percepción que tenemos las personas sobre la realidad en la que vivimos hoy en día. Una realidad en la que conviven los Deep Fake y los movimientos \#metoo, el auge de la ultraderecha populista y las filtraciones como Wikileaks. Una realidad cada vez más extraña, menos clara y más llena de incertidumbres. Una realidad que transita entre un mundo que no termina y otro que no acaba de arrancar del todo. En este último sentido la Pandemia ha supuesto un "choque entre el viejo mundo y el nuevo que se había aplazado durante demasiado tiempo, con reglas para el enfrentamiento que impidieron que estallara de verdad" (Baricco, 2021: 78).

MITO Collective, en diálogo con sus conciudadanos sobre su percepción y vivencia de la realidad en esa época de confinamiento, generó unos lemas que difunde todavía hoy (hay que considerar que el proyecto sigue vivo) por todo el mundo a través de proyecciones lumínicas sobre fachadas de edificios hechas por los mismos espectadores de la obra. Una obra que consiste en su dimensión más visible en estas proyecciones y su documentación mediante fotografías, pero que también consta de correos electrónicos, llamadas de teléfono, conversaciones vía whatsapp, préstamos de proyectores... 


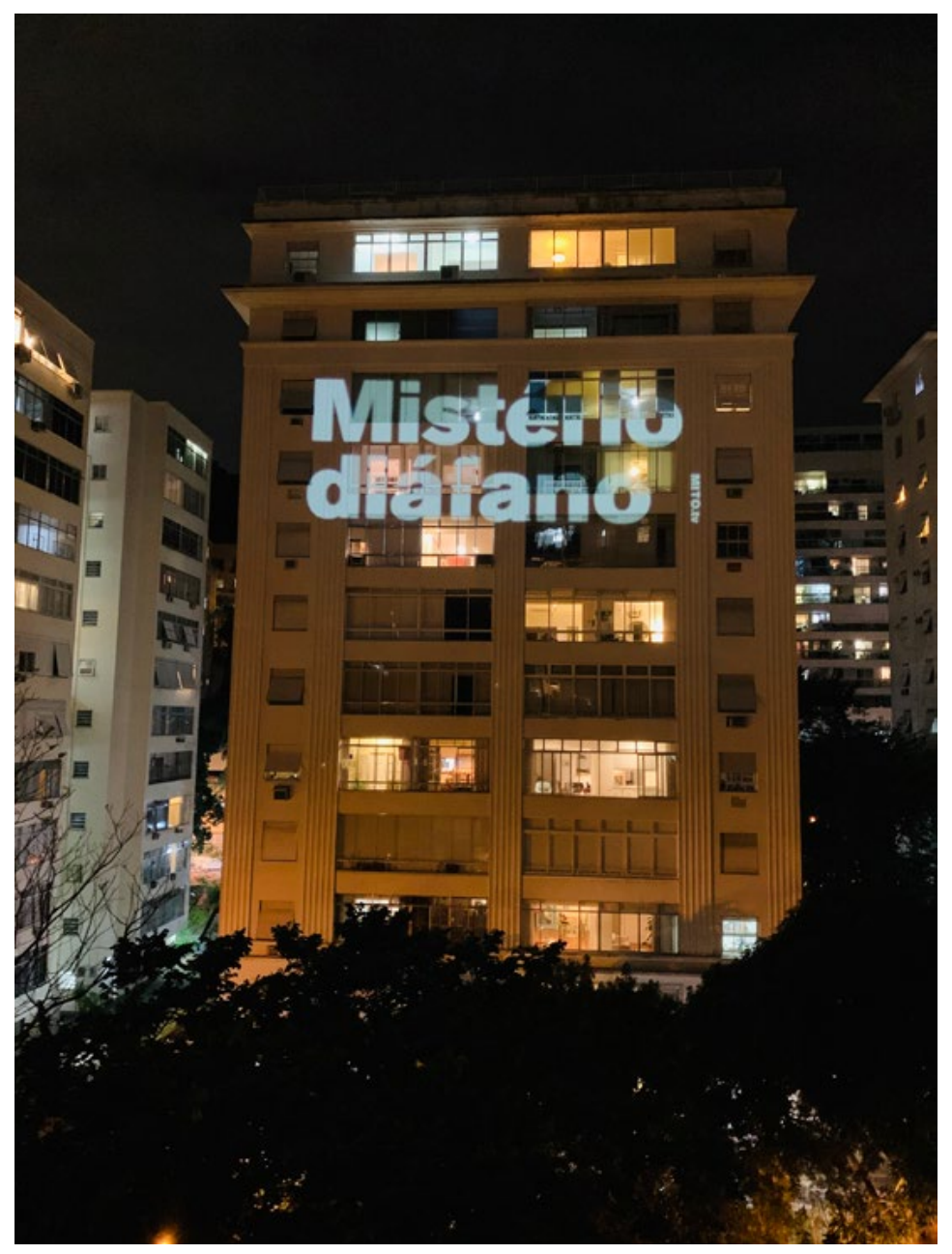

Figura 6. El lema Misterio diáfano sobre una fachada en Rio de Janeiro, Brasil. Fuente: Irrealidad Aumentada. MITO Collective (2021).

Entendimos la explosión de la pandemia mundial de coronavirus y el encierro en el que derivó como detonante de un tiempo de suspenso —en el que todo el mundo se encontró encerrado en casa, sin poder salir, sin trabajo, sin relaciones sociales, sin espacios de ocio-. Un paréntesis temporal parecido al tiempo de un concierto, en el que el tiempo cronológico se suspende y rige el tiempo musical, que escapa a la dictadura del reloj (Hersch, 2013). De manera análoga al concierto, el tiempo todavía aparentemente ordenado por el antiguo ora et labora benedictino de la producción capitalista, pasaba, con el confinamiento domiciliario, a estar fundido en un amasijo de horas en las que trabajar, consumir y descansar estaban mezcladas y eran indistinguibles. Navegar entre las ofertas de Amazon a la vez que se atiende a 
una videollamada de trabajo y se prepara la comida era una situación perfectamente imaginable en ese momento en que la subsistencia, la producción y el consumo se entrelazaban.

Pretendimos convertir esa suspensión, ese espacio en blanco, en un momento de reflexión, de crítica y de acción. Aprovechar para asestar una cuchillada más en el cuerpo maltrecho del paradigma cartesiano y capitalista y abrir todavía más el debate sobre la revolución epistemológica que reclama Preciado (2020). Todo ello para construir un mito que dotara de "un perfil legible a un puñado de hechos" traduciendo "lo indiferenciado que es propio de lo que sucede a la forma completa que es propia de lo que es real" (Baricco, 2021, p. 3). Es decir, un mito que abriera la posibilidad para una nueva epistemología, considerando que "una epistemología determina un orden de lo visible y lo invisible, por tanto una ontología y un orden de lo político; es decir, determina la diferencia entre lo que existe y lo que no existe, y establece una jerarquía" (Preciado, 2020, p. 60).

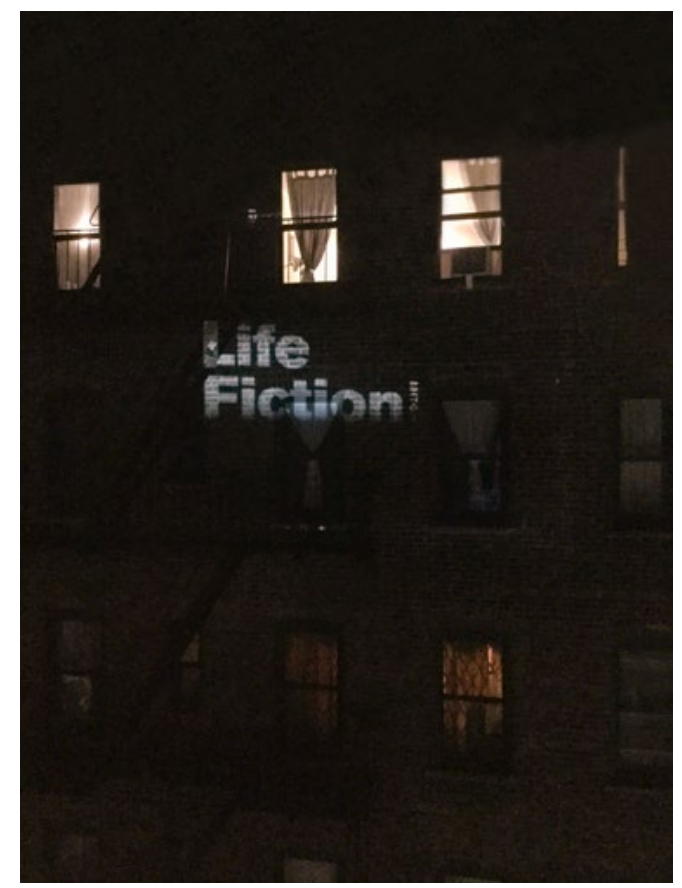

Figura 7. El lema Vida ficción sobre una fachada en Nueva York, EUA.Fuente: Irrealidad Aumentada. MITO Collective (2021). 
Es evidente que, partiendo desde esta perspectiva de abrir el debate hacia un nuevo reparto de lo sensible, una nueva comprensión del mundo y, consecuentemente, una nueva realidad, es necesario cuestionar las estructuras asumidas por el arte y sus funciones. Quién es el artista, quién es el público, qué es la obra de arte e incluso sus canales de distribución, exhibición e incluso sus tiempos y su alcance geográfico y demográfico. Había que situar a todos los participantes en una posición de mediador, de acuerdo con el significado que Latour da a esta noción.

Para Latour (2008), en su visión performativa de lo social, las "fuerzas sociales", es decir, los medios para producir lo social, pueden entenderse desde dos ópticas distintas, como intermediarios o como mediadores. Un intermediario es, para Latour, aquello "que transporta significado o fuerza sin transformación: definir sus datos de entrada basta para definir sus datos de salida". Los mediadores, en cambio, "transforman, traducen, distorsionan y modifican el significado o los elementos que se supone que deben transportar". "Sus datos de entrada nunca predicen bien los de salida; su especificidad debe tenerse en cuenta cada vez" (Latour, 2008, pp. 61-63). Había que empezar a prestar atención (Ingold, 2017) a esta realidad que queríamos analizar y sobre la que pretendíamos intervenir.

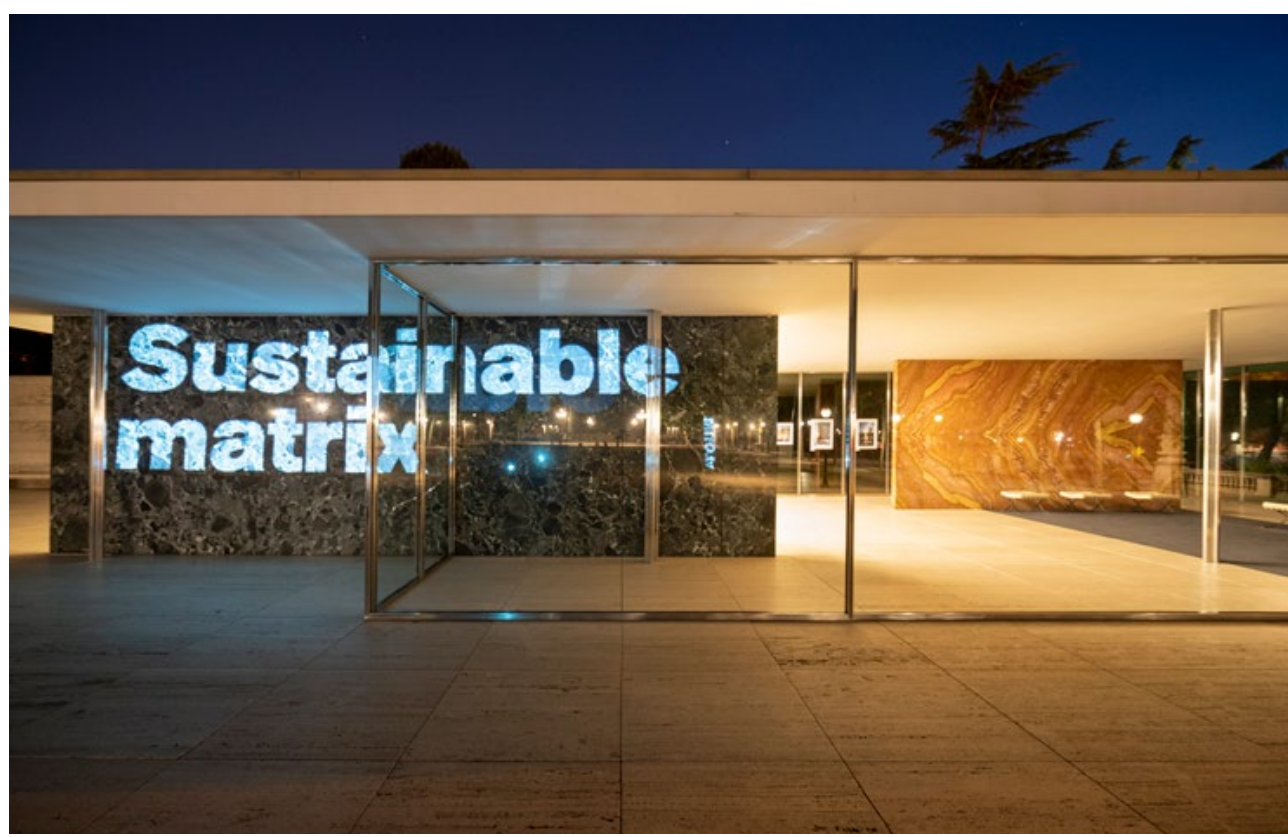

Figura 8. El lema Matrix sostenible sobre la fachada del pabellón Mies van der Rohe, Barcelona, España. Fuente: Irrealidad Aumentada. MITO Collective (2021). 
Desde esta perspectiva, pues, las figuras de público y creador y el rol de las instituciones y la forma de la exposición dejan de tener el sentido tradicional. El público deja de ser un receptor de una creación hecha por un artista en el marco de un programa creado por una institución y que toma la forma de exposición. Si el artista y el público se colocan en un papel de lo que Latour llama mediación no cabe un público pasivo que transformar, cabe un público que medie y que transforme, un público que distorsione la salida, que actúe, que sea agente activo en la transformación. Entendiendo esta nueva posición, la exposición, la exhibición de la obra, deja de ser un lugar estático, un resultado, una narración cerrada, para ser un evento impredecible, un espacio-tiempo en el que la mediación ocurre y cuyas consecuencias se expanden más allá de los límites del evento y del arte.

Prestar atención, tal y como lo define Tim Ingold (2017), es un camino del medio que obliga a replantearse los métodos y los roles preestablecidos. No se trata de situarse en el paradigma extractivo de los datos de las ciencias duras ni tampoco en el extremo contextual y soft de las humanidades. Se trata de generar dinámicas de retroalimentación, de reconocer agencias y situaciones y de establecer un contacto respetuoso y transformador.

Es aquí donde Toward a Lexicon of Usership (Whright, 2013) y sus reflexiones pueden abrirnos caminos. En este texto, Stephen Wright, reflexiona en torno al concepto de usabilidad en el arte que pone en cuestión la cultura del experto, la figura del espectador y el régimen de propiedad. Sus aportaciones alrededor del concepto de usabilidad y sus repercusiones en el sistema arte y, en consecuencia, en el mundo.

En lo que aquí nos toca, el texto nos interesa porque las prácticas artísticas orientadas al usuario trabajan con lo cotidiano y lo cooperativo, llegando a desactivar en gran parte su función estética/artística, lo que significa que se trata de prácticas que pueden pasar desapercibidas como prácticas artísticas, pues pueden tomar la forma de encuentros, reuniones, asociaciones, formaciones, actos reivindicativos... Proyectar lemas sobre fachadas, dinámica en la que Irrealidad aumentada se formaliza, fue una vía que encontraron muchas reivindicaciones para tomar forma alrededor del mundo y que permitía que cualquiera con un proyector en casa pudiera transmitir mensajes a sus vecinos sin saltarse la prohibición de estar en la vía pública. 


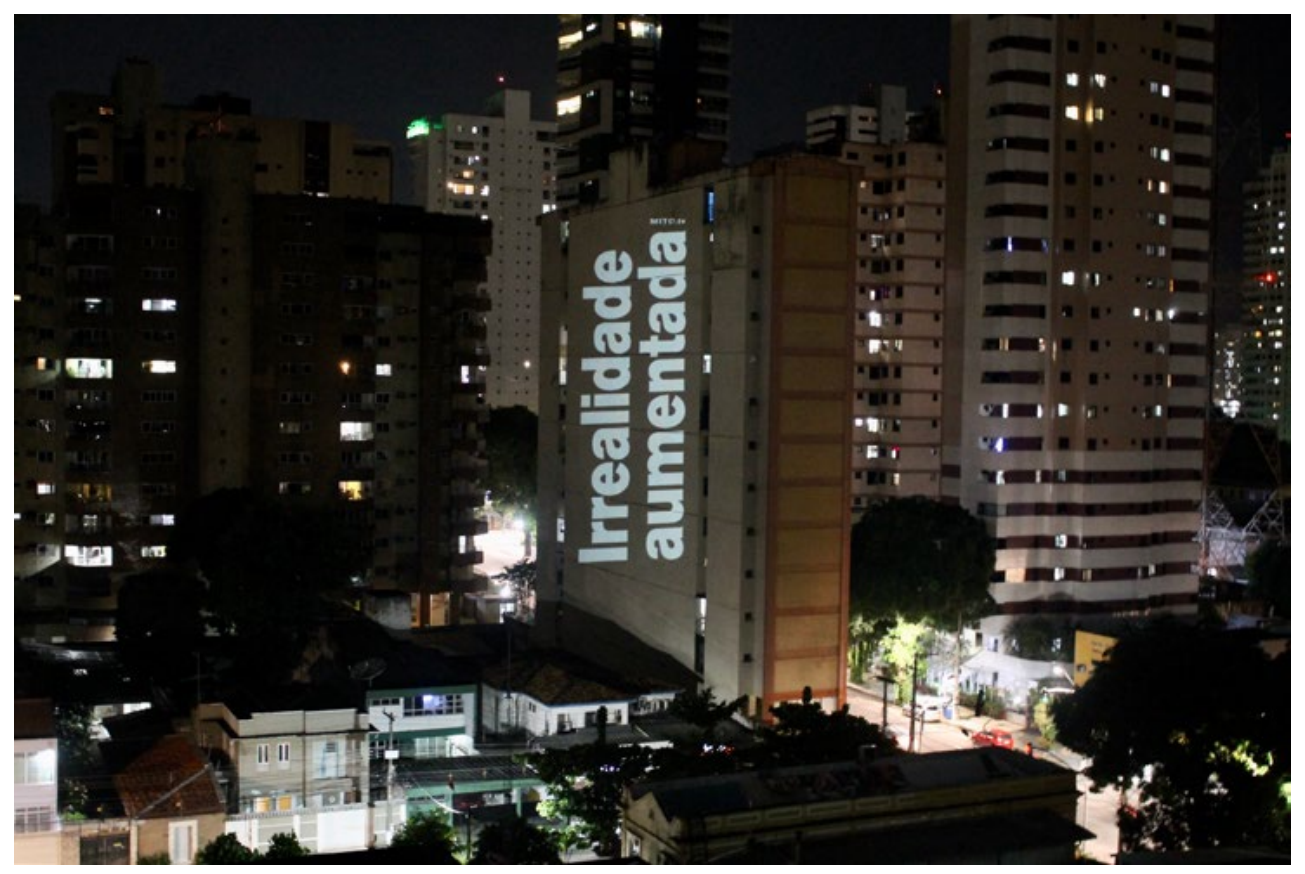

Figura 9. El lema Irrealidad aumentada sobre un edificio en Belem, Brasil. Fuente: Irrealidad Aumentada. MITO Collective (2021).

Se trata de prácticas que tienen lo que Wright (2013) llama una doble ontología. Este tipo de proyectos son, por un lado, lo que parece que son: intervenciones, prácticas, acciones que, a priori, no tienen ninguna función estética/artística o que, como mínimo, tienen esta función desactivada. Por otro lado, son proposiciones artísticas de lo que son. Tienen una voluntad de intervenir en el mundo, y en este sentido tienen potencial ontogenético, pero se piensan en tanto que obra de arte, re-activando en cierto modo esta función estética/artística que, en ocasiones puede servir como pasaporte a prácticas que, de no ser artísticas, no se permitirían (Fontdevila, 2018).Bajo el paradigma de la usabilidad de Wright (2013) y de la mediación de Latour (2008), Irrealidad aumentada se convierte en un mito, considerando que:

Las criaturas míticas no forman en sí mismas sistemas coherentes. El mito es una red rota. No genera orden, sino definición: nombra, pero no regula; marca, pero no armoniza; enumera, pero no calcula. El Mito restituye la sustancia irresoluble de los humanos. Es un libro de contabilidad donde el debe y el haber no producen un resultado final, sino muchos resultados posibles. (Baricco, 2021, p. 46) 
Irrealidad aumentada teje redes, une puntos inconexos del mundo, pero no los resuelve en un intercambio de información, simplemente, los sitúa como espacios de intervención y reflexión.

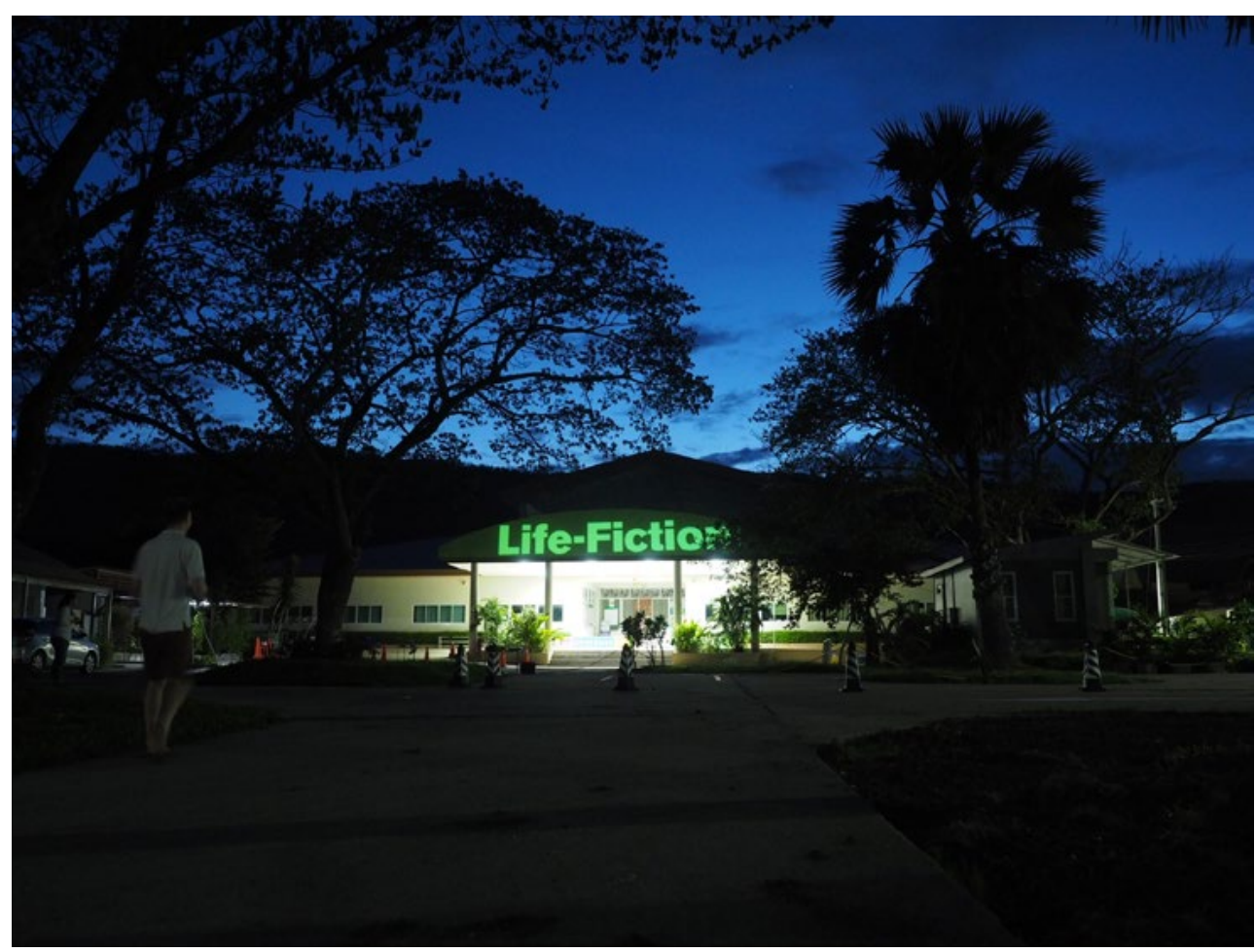

Figura 10. El lema Vida ficción sobre el dintel de la entrada de una escuela en Takhli, Tailandia. Fuente: Irrealidad Aumentada. MITO Collective (2021).

En este sentido, entendemos esta relación entre el artista y el público como la relación que establece Rancière entre maestro y estudiante en El maestro ignorante (2003) o entre el público y el artista en El espectador emancipado (2008). Una relación en la que el estudiante/espectador aprende del maestro/ artista, con el maestro/artista, algo que el maestro/artista ignora, en la que se abole un transmisión de saber, de significado del uno al otro puesto que no hay que salvar ninguna brecha entre unos y otros, entre los que ponen en marcha el proceso, los que cogen el testigo y deciden actuar y, finalmente, los que simplemente lo observan. Porque:

$[\ldots]$ en un teatro, ante una performance, igual que en un museo, una escuela o una calle, nunca hay más que individuos que trazan su propio camino en la selva de cosas, de actos y de signos que los encaran y los rodean. El poder común a los espectadores (...) es el poder que tiene cada uno o cada una de traducir a su 
manera lo que él o ella percibe, de ligarlo a la aventura intelectual singular que los hace semejantes a cualquier otro en la medida en que dicha aventura no se parece a ninguna otra (Rancière, 2008, p. 22).

Aquí, el ciudadano ya no es solo un espectador emancipado y crítico, sino que interviene directamente en el reparto de lo sensible. Se apodera de los medios de producción de significado, interviene en ellos, es decisivo para que existan. Sin el espectador, ahora ya ciudadano-artista, que proyecta los lemas en las fachadas de sus vecinos para que sean leídos no hay obra, no hay arte, no hay conocimiento, no hay metáfora. Él es a la vez espectador, creador y dispositivo de exhibición. Él recoge aquello que el artista, MITO Collective, le hace llegar después de mediar con sus sensaciones, sentimientos y reflexiones con la realidad, y lo transforma tomando decisiones clave en la obra: su duración, su espacio de visibilidad, su momento de aparición, el registro de esta aparición. También, en consecuencia, lidia con las posibles consecuencias de su actuación, que entendemos también forman parte de la obra: desde críticas de los vecinos a aplausos, desde intentos de boicot de la proyección a interés porque vuelva a producirse; todo ello, traducciones y apropiaciones y mediaciones de y con la obra.

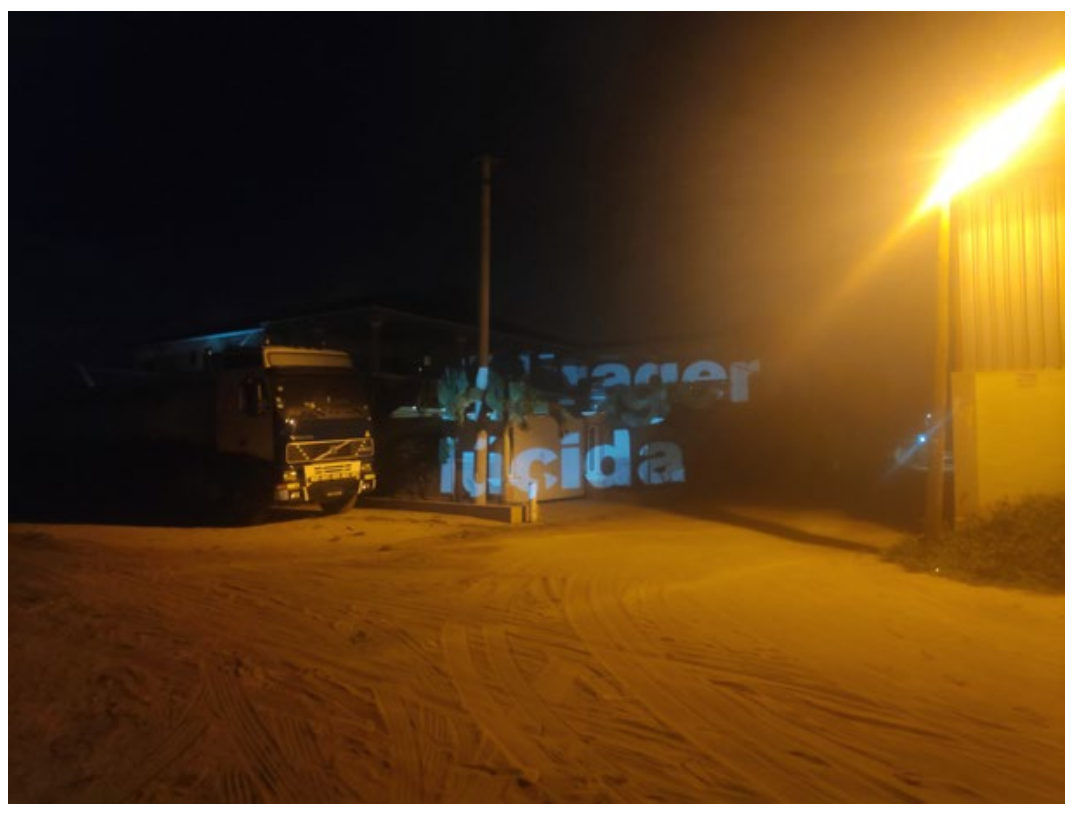

Figura 11. El lema Espejismo lúcido sobre en una calle de Luanda, Angola. Fuente: Irrealidad Aumentada. MITO Collective (2021). 
Digamos que, recuperando la definición de obra de arte que hizo Gell (1998), si la principal razón de existir de una obra de arte es afectar a la comunidad que alberga, recogiendo sus anhelos y los temores, las creencias y miedos, el artista es el que genera aquello que afecta y actúa generando la comunidad. Por su parte, la sociología de las asociaciones de Latour (2008) nos muestra que las asociaciones desaparecen cuando ya no son actuadas y, terminada la actuación, su permanencia solamente puede indicar que otros actores han tomado el relevo de los primeros. Consecuentemente, en Irrealidad aumentada, la figura de artista se disuelve entre los ciudadanos que pasan a desempeñar el papel de generar la comunidad y afectarla. Así pues, los ciudadanos devienen artistas y los artistas ciudadanos.

\section{Un pueblo por venir}

Si la razón de existir del arte, siguiendo a Gell (1998), es esta creación y afectación de la comunidad, es evidente que cualquier obra de arte es política, es decir, pretende mover la sociedad y definir, afianzar, cuestionar, criticar o replantear cómo nos constituimos como sociedad y qué nos define como tal, cuáles son nuestros límites y/o cuáles son los principios que nos rigen. Irrealidad Aumentada, como ya hemos explicado, pretende abrir la reflexión sobre el mundo en el que vivimos usando el poder de lo poético y la metáfora.

La metáfora, en el caso de Irrealidad aumentada, hay que entenderla a partir de la definición de Ortega y Gasset: “

la metáfora nos satisface precisamente porque en ella averiguamos una coincidencia entre dos cosas más honda y decisiva que cualesquiera semejanzas" (Ortega y Gasset, 2009, p. 165). 


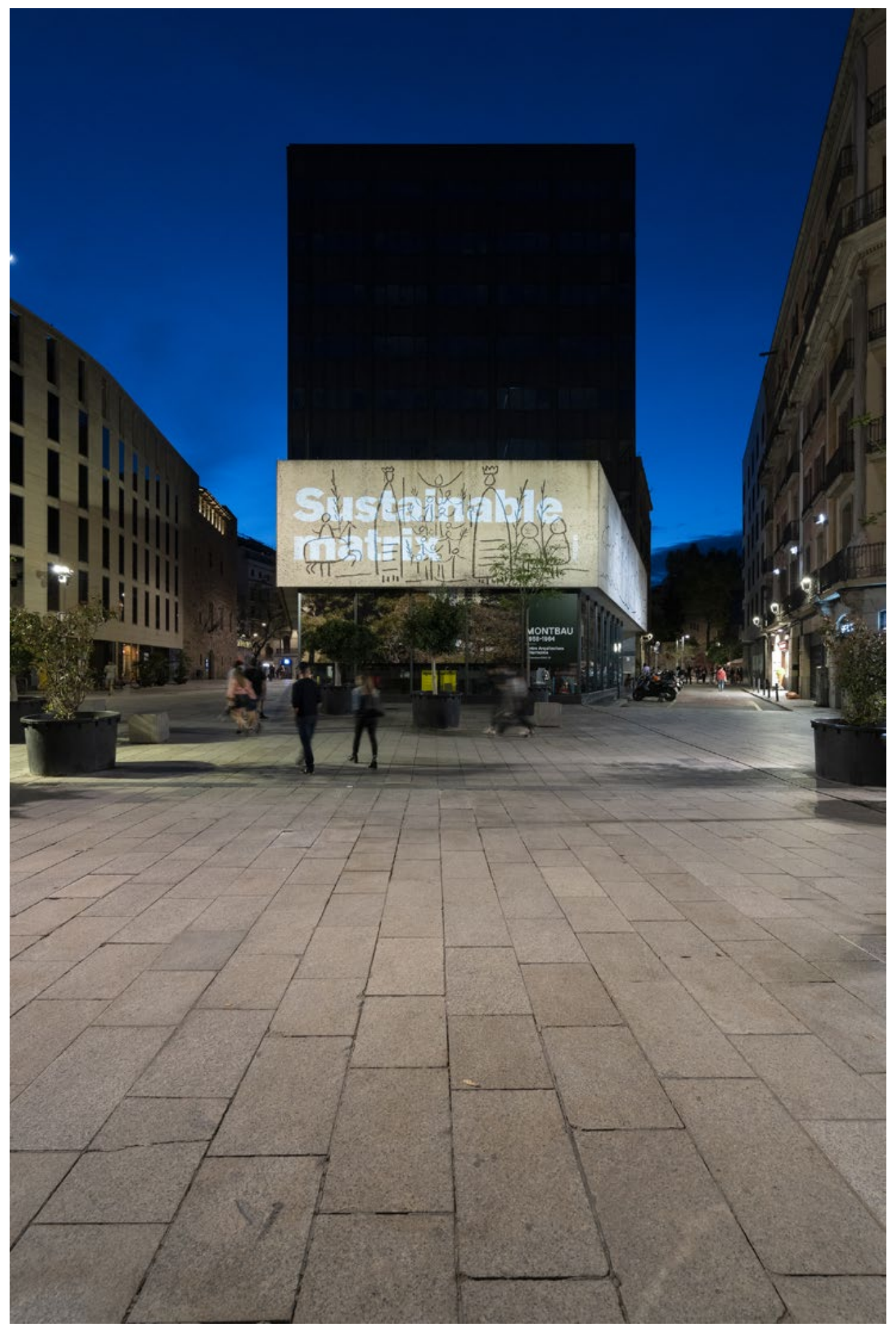

Figura 12. El lema Matrix Sostenible sobre la fachada del COAC, Barcelona, España. Fuente: Irrealidad Aumentada. MITO Collective (2021). 
Para que ocurra este instante de averiguación de la coincidencia honda, sigue Ortega y Gasset,

necesitamos del parecido real, de cierta aproximación capaz de ser razonada entre dos elementos, más con un fin contrario al que suponemos. Adviértase que las semejanzas donde las metáforas se apoyan son siempre inesenciales desde el punto de vista real. En nuestro ejemplo [el ciprés llama] la identidad del esquema lineal entre un ciprés y una llama es de tal modo extrínseca, insignificante para cada uno de muchos elementos, que no vacilamos en considerarla como un pretexto. El mecanismo, pues, acaso sea el siguiente: se trata de formar un nuevo objeto que llamaremos el «ciprés bello», en oposición al ciprés real. Para alcanzarlo es preciso someter éste a dos operaciones: la primera consiste en libertarnos del ciprés como realidad visual y física, en aniquilar el ciprés real; la segunda consiste en dotarlo de esa nueva cualidad delicadísima que le presta carácter de belleza. (Ortega y Gasset, 2009, p. 166)

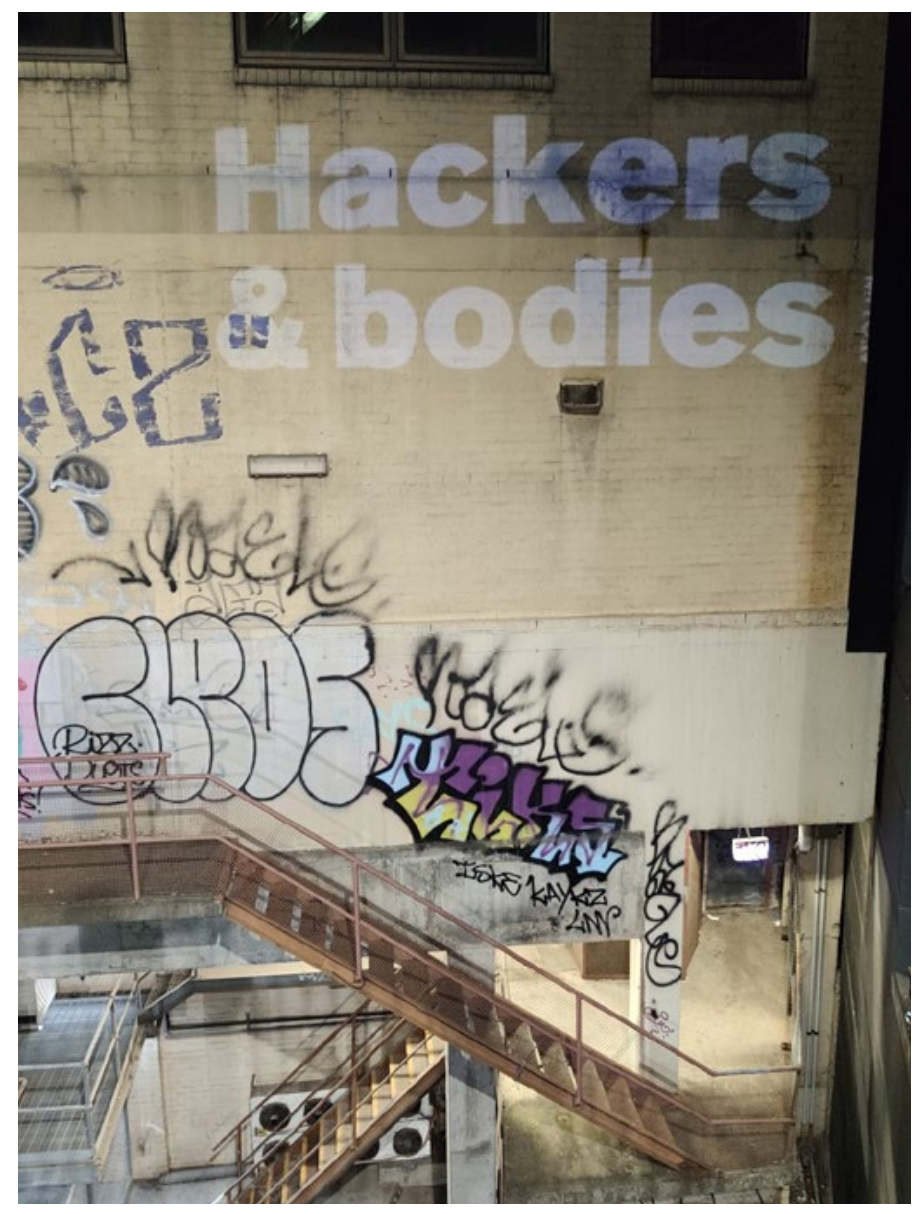

Figura 13. El lema Hackers \& cuerpos sobre la un edificio en Sydney, Australia. Fuente: Irrealidad Aumentada. MITO Collective (2021). 
Los lemas que se proyectan en cada aparición de Irrealidad aumentada, unen, por un lado, el significado de dos palabras alejadas entre sí que se afectan mutuamente y, por otro, el resultado de esta operación con el contexto social, tecnológico, sanitario, político y económico de cada comunidad que lee y busca entender el significado de lo proyectado. Las infinitas posibilidades de cada lema se concretan en cada lector, en cada observador, en cada espectador, que se convierte en parte imprescindible de la obra ya que, tal y como Harman (2020) describe, es esencial para que la metáfora se performe y ésta devenga la herramienta más útil para intentar acceder a la realidad. En resumen, podríamos entender que no hay arte si no se toma partido, si no se decide una de entre una multiplicidad de opciones.

Así pues, MITO Collective genera lemas pretendidamente inconcretos y poco definidos en los que resuenan conceptos tecnológicos, de control, de la cultura pop, juegos de palabras, oxímoros... Brevedad y separación entre las palabras para que el antiguo espectador, ahora ciudadano-artista, rellene los huecos de significado y se movilice ante la necesidad del cambio epistemológico ya analizado.

\author{
Irrealidad aumentada. \\ Imperio líquido. \\ Snacks \& doctrina. \\ Hackers \& cuerpos. \\ Espejismo lúcido. \\ Misterio Diáfano. \\ Vida Ficción. \\ Matrix Sostenible.
}

Estos lemas en tiempo de pandemia y confinamiento domiciliario se sitúan como una herramienta para reforzar un pensamiento de lo impensable que ya es inherente en la propia situación. Este encierro forzado por un virus mortal,

durante un largo tiempo, suspende la secuencia lógica que hacía que cualquier mundo diferente a este pareciera imposible, produciendo una apnea en el sistema. Rompe las cadenas de lo inevitable y, al incluir experiencias inéditas, les devuelve a los humanos la capacidad de pensar lo impensable: no como un juego de la fantasía, sino como una técnica de construcción, como una forma de racionalidad. (Baricco, 2021, p. 76) 


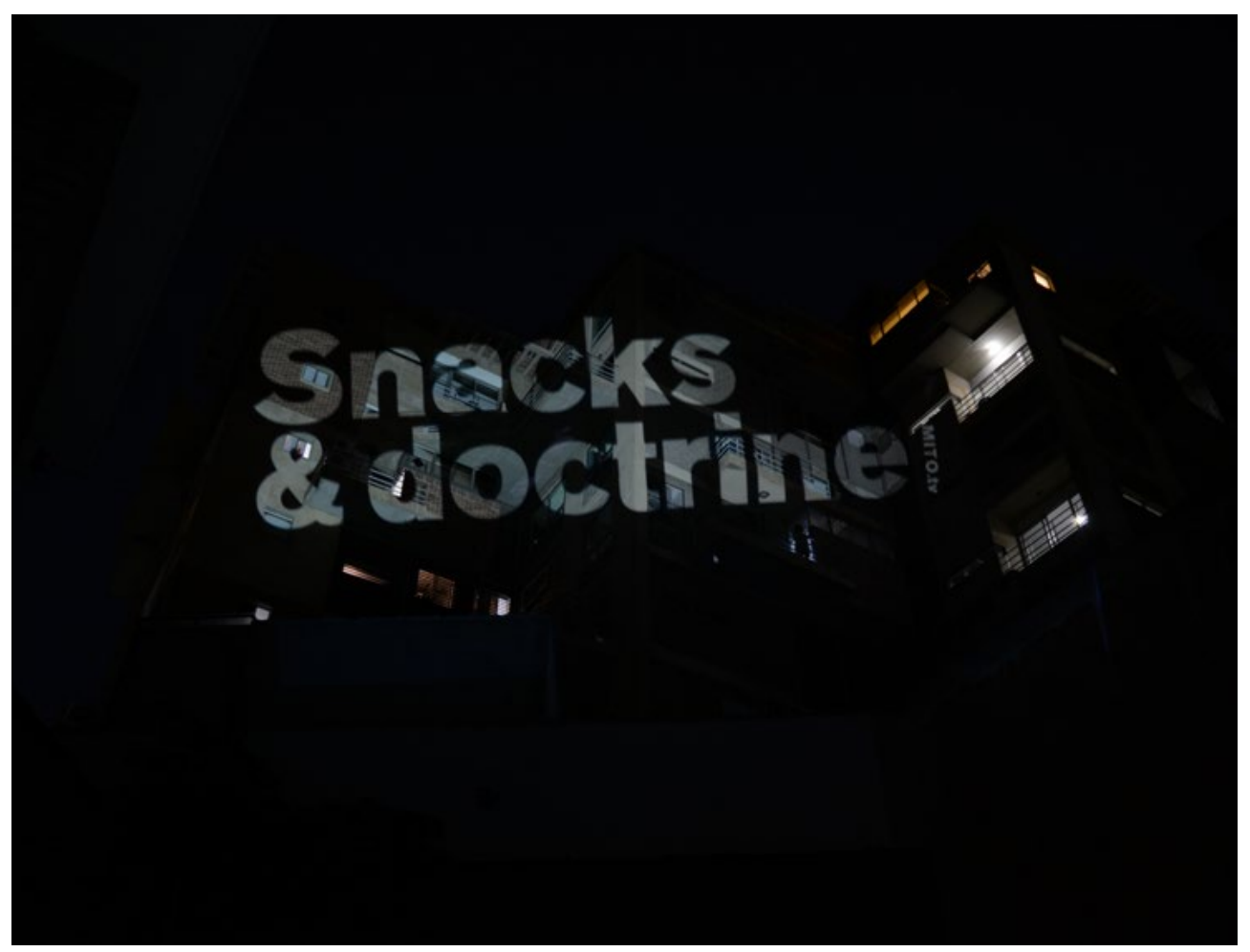

Figura 14. El lema Snacks \& doctrina sobre un edificio en Cúcuta, Colombia. Fuente: Irrealidad Aumentada. MITO Collective (2021).

Irrealidad aumentada se puede entender, bajo esta perspectiva, como una herramienta para abrir la ventana de Overton (Lehman, 2010) hacia el espacio de la libertad, situando aquello impensable más cerca de la política, ya que los ciudadanos son invitados a reflexionar y tomar partido, a través de estos lemas, sobre la situación y el contexto en el que viven. Una herramienta que aspira no a quedarse en la metáfora poética sino en devenir hiperstición.

Una hiperstición es un lugar en el que "la realidad objetiva y la supersticiosa — la de las ideas y el hype — se fusionan en una nueva realidad reconstruida, es decir: las hipersticiones no solo ingresan a nuestra realidad sino que además la actualizan" (Sanchiz, 2019). Es, pues,

una suerte de ficción, pero que apunte a convertirse en verdad. Las hipersticiones funcionan catalizando un sentimiento disperso en una fuerza histórica que haga realidad el futuro. Tienen la forma temporal del «habrá sido». Tales hipersticiones del progreso conforman narrativas que orientan, con las cuales se puede navegar hacia delante y no son una propiedad establecida o necesaria del mundo. (Srnicek, 2018, p. 95) 
Debemos entender que es voluntad del proyecto transformar la realidad y devenir agente del cambio, ser parte del corpus que genera el pensamiento antes impensable, abrir la ventana de Overton a aquello que está quedando fuera, ayudando a nuevas epistemologías a ser posibles, pensables y practicables.

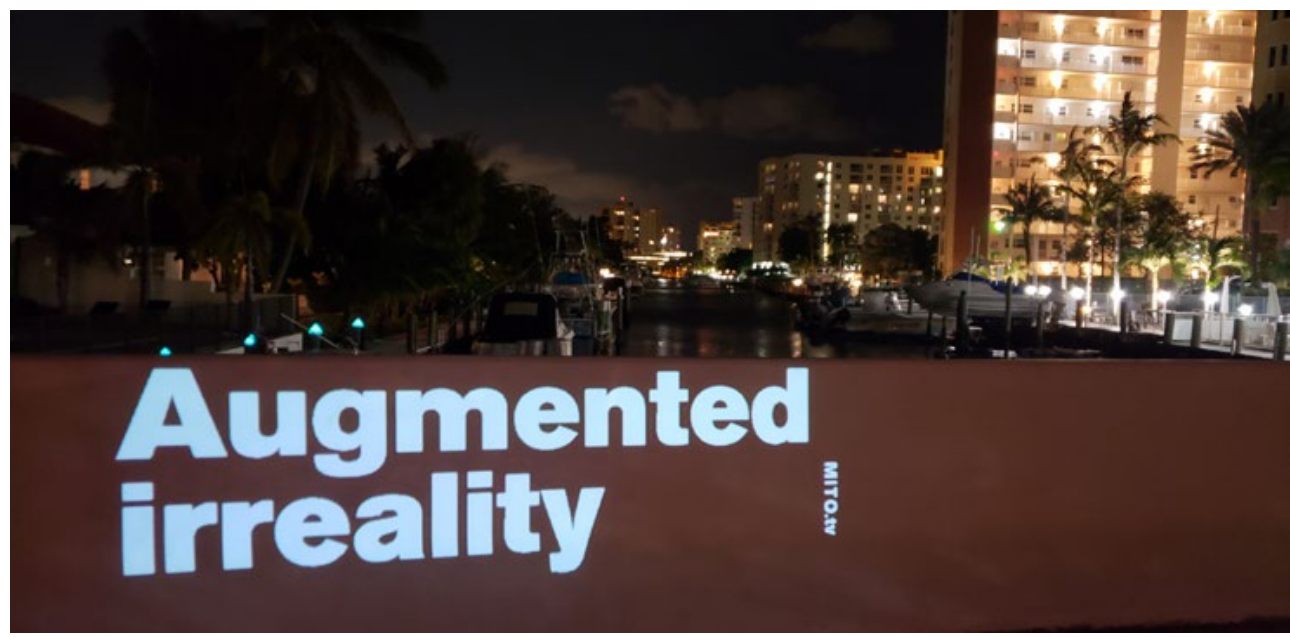

Figura 15. El lema Irrealidad aumentada en las calles de Miami, EUA. Fuente: Irrealidad Aumentada. MITO Collective (2021).

Para Baricco (2021), la figura mítica de la Pandemia se mantiene unida gracias a la tensión de dos fuerzas enormes y contrarias. La primera de ellas es una fuerza que tiende a restaurar el status quo previo a la pandemia indemnizando incluso a los detentores del poder, restaurando aquello que podían haber perdido en los últimos tiempos, "la pandemia ha acabado por afilar las garras de un poder que estaba perdiendo su presa" (Baricco, 2021, p. 75). La segunda fuerza, en el sentido contrario "le quita, por así decirlo, un latido a las pulsaciones del poder" (Baricco, 2021, p. 75), lo que "coloca a los humanos frente a auténtica figura de la utopía” (Baricco, 2021, p. 76).

Nos queda por decidir sobre qué utopía estamos hablando y cuál es nuestra propuesta. Hardt y Negri en Imperio (2005, p. 89-111) explican dos momentos o movimientos de la Modernidad europea. En el primero, que asocian con la activación de un plano de inmanencia, se producen nuevas formas de vida relacionadas con el deseo y la asociación, el amor a la comunidad. El segundo es una reacción al primero, una captura de este por un aparato de control y clasificación, la instalación de un régimen de trascendencia. 


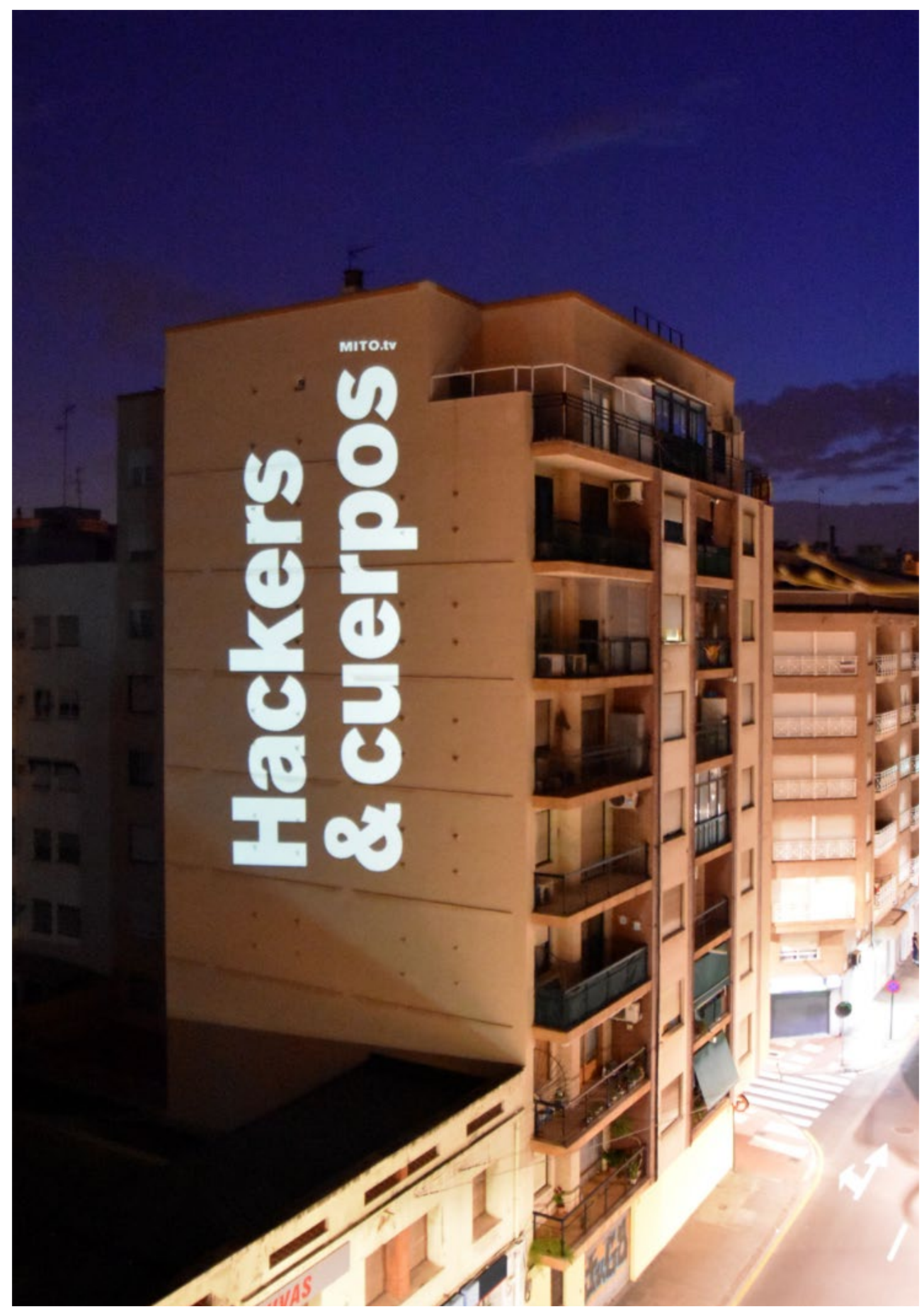

Figura 16. El lema Hackers \& cuerpos sobre un edificio de Castellón de la Plana, España. Fuente: Irrealidad Aumentada. MITO Collective (2021).

El arte políticamente comprometido suele entender la resistencia como secundaria (producida por un estado represivo), por lo que ataca al segundo 
momento y olvida el primero. Se contenta con el rechazo y la disensión en una especie de crítica negativa que tiene que ver con un estilo de pensamiento en el que la resistencia se entiende como reacción a un estado autoritario y represivo. De este modo, el arte políticamente comprometido estará determinado por aquello contra lo que se posiciona, aquello contra lo que reacciona, que se convierte de nuevo en un aparato de captura que le impone sus límites. Si, por otra parte, vemos la resistencia como lo primario y el aparato como lo secundario (como capturando su vida), el arte políticamente comprometido tiene la capacidad de involucrarse, de apostar por la afirmación de este momento previo ontológico. Esta afirmación del primer momento de la Modernidad es, pues, una afirmación de la multitud, del "pueblo-que-estápor-venir" (O'Sullivan, 2006: 77).

Un pueblo que, desde la complejidad de la cosmopolítica (Stengers, 2018), ha construido y sigue construyendo un proyecto, Irrealidad aumentada, que afirma que estamos en un momento de cambio ontológico y epistemológico y que propone nuevas formas de colaborar, crear y generar una nueva realidad a través del arte y lo poético.

\section{Referencias}

Baricco, Alessandro. 2021. Lo que estábamos buscando. De la pandemia como criatura mítica. Barcelona: Anagrama.

Fontdevila, Oriol. 2018. El arte de la mediación. Bilbao: Consonni.

Gell, Alfred. 1998. Art and Agency. Oxford: Clarendon Press.

Hardt, Michael; Negri, Antonio. 2005. Imperio. Barcelona: Paidós.

Harman, Graham. 2020. Art + Objects. Cambridge: Polity Press.

Hersch, Jeanne. 2013. Tiempo y música. Barcelona: Acantilado.

Ingold, Tim 2017. The art of paying attention. Keynote leída en Art of Research Conference 2017: Art as a catalyst!. Helsinki: Aalto University school of arts, design and architecture. [Disponible en http:// artofresearch2017.aalto.fi/keynotes.html]

Latour, Bruno. 2008. Reensamblar lo social. Una introducción a la teoría del actor-red. Buenos Aires: Manantial.

Lehman, Joseph G. 2010. An introduction to the Overton window of political possibility. En Mackinac Center for Public Policy, publicado el 08/04/2010. [Disponible en https://www.mackinac.org/12481] 
Ortega y Gasset, José 2009 [1925]. Ensayo de estética a manera de prólogo. En La deshumanización del arte de José Ortega y Gasset. Madrid: Alianza Editorial. pp.152-174.

O'Sullivan, Simon. 2006. Art encounters Deleuze and Guattari. Though Beyond Representation. New York: Plagrave Macmillan

Preciado, Paul. 2020. Yo soy el monstruo que os habla. Barcelona: Anagrama.

Rancière, Jacques. 2003. El maestro ignorante. Cinco lecciones sobre la emancipación intelectual. Barcelona: Laertes.

Rancière, Jacques. 2008. El espectador emancipado. Castellón: Ellago Ediciones.

Sanchiz, Ramiro. 2019. Glosario hipersticional. En Nick Land, Flanged Noumena vol. 1. Barcelona: Holobionte Ediciones.

Srnicek, Nick; William, Alex. 2018. Reinventar el futuro. Postcapitalismo y un mundo sin trabajo. Barcelona: Malpaso.

Stengers, Isabelle. 2018. Another Science is possible. A manifesto for slow science. Cambridge: Polity Press.

Wright, Stephen. 2013. Toward a lexicon of usership. Eindhoven: Van Abbemuseum. [Disponible en https://museumarteutil.net/wp-content/uploads/2013/12/Toward-alexicon-of-usership.pdf] 
